\title{
When does less yield more? The impact of severity upon implicit recognition in pure alexia
}

\author{
Daniel J. Roberts, Matthew A. Lambon Ralph, Anna M. Woollams* \\ Neuroscience and Aphasia Research Unit, School of Psychological Sciences, University of Manchester, Manchester, UK
}

\section{A R T I C L E I N F O}

\section{Article history:}

Received 24 August 2009

Received in revised form 9 February 2010

Accepted 1 April 2010

Available online 18 April 2010

\section{Keywords:}

Pure alexia

Letter-by-letter reading

Implicit recognition

Frequency

Imageability

\begin{abstract}
A B S T R A C T
Pure alexia (PA) is characterised by strong effects of word length on reading times and is sometimes accompanied by an overt letter-by-letter (LBL) reading strategy. Past studies have reported "implicit recognition" in some individual PA patients. This is a striking finding because such patients are able to perform semantic classification and lexical decision at above chance levels even when the exposure duration is short enough to prevent explicit identification. In an attempt to determine the prevalence of this "implicit recognition" effect, we assessed semantic categorisation and lexical decision performance using limited exposure durations in 10 PA cases. The majority of the patients showed above chance accuracy in semantic categorisation and lexical decision. Performance on the lexical decision test was influenced by frequency and imageability. In addition, we found that the extent to which patients showed evidence of "implicit recognition" in both tasks was inversely related to the severity of their reading disorder. This result is consistent with hypotheses which suggest that this effect does not constitute an implicit form of unique word identification but is a reflection of the degree of partial activation within the word recognition system. These results also go some way towards explaining the individual variation in the presence of this effect observed across previous case-study investigations in the literature.
\end{abstract}

(C) 2010 Elsevier Ltd. All rights reserved.

\section{Introduction}

Pure alexia (PA) is an acquired reading disorder associated with damage to the left occipito-temporal region. Behaviourally, the reading performance of PA patients is characterised by abnormally strong effects of word length on reaction times and/or accuracy (Behrmann, Plaut, \& Nelson, 1998). More severe cases are also characterised by an explicit and laborious letter-by-letter (LBL) reading strategy, which exacerbates the negative impact of length upon reading performance (Lambon Ralph, Hesketh, \& Sage, 2004). In terms of the functional cause of PA, two broad classes of explanation can be distinguished. The first account implicates damage to early components of a dedicated reading system, such as the orthographic lexicon or letter identification system, preventing normal parallel letter processing which underpins rapid and accurate word identification (Arguin \& Bub, 1993; Bub \& Arguin, 1995; Howard, 1991; Saffran \& Coslett, 1998; Warrington \& Shallice, 1980). The second account proposes that the reading problem arises as a consequence of a more general visual processing deficit which shows itself readily with orthographic stimuli due to the intrin-

\footnotetext{
* Corresponding author at: Neuroscience and Aphasia Research Unit, School of Psychological Sciences, Zochonis Building, University of Manchester, Brunswick Street, Manchester M13 9PL, UK. Tel.: +44 161306 0453; fax: +44 1612752873.

E-mail address: anna.woollams@manchester.ac.uk (A.M. Woollams).
}

sically high demands they place on the visual system (Behrmann, Nelson, \& Sekuler, 1998; Behrmann, Plaut, et al., 1998; Behrmann \& Shallice, 1995; Farah \& Wallace, 1991; Friedman \& Alexander, 1984; Mycroft, Behrmann, \& Kay, 2009; Starrfelt, Habekost, \& Gerlach, 2010). The perceptual deficit account is supported by the findings that: (a) in nearly all PA patients where pre-lexical visual processing has been assessed, a deficit has been apparent (Behrmann, Plaut, et al., 1998); and (b) recognition deficits in PA patients also extend to the processing of other non-orthographic visual stimuli such as object pictures (Behrmann, Nelson, et al., 1998) and checkerboard patterns (Mycroft et al., 2009).

Within the perceptual deficit account of PA (Behrmann, Nelson, et al., 1998), the explicit LBL reading observed amongst many PA patients represents a strategy that attempts to boost the input signal to the reading system and thereby improve reading performance. In addition, to the extent that processing within the reading system is cascaded and interactive (McClelland \& Rumelhart, 1981; Plaut \& Shallice, 1993), weak initial partial activation of higher order lexical and semantic representations may feedback to facilitate processing at the level of letter identification. This interactive account proposes that the reading performance of PA patients should be sensitive to lexico-semantic variables such as frequency and imageability. Indeed, frequency and imageability effects have been observed in the reading aloud performance of some PA patients but have not been apparent in the performance of others (Behrmann, Plaut, et al., 1998). One potential account for the variability in the 
magnitude of lexico-semantic effects amongst PA patients is that the opportunity for top-down influence is related to the severity of the reading disorder in the form of an inverted U-shaped function (Behrmann, Plaut, et al., 1998). For relatively mild patients, reading is reasonably rapid and there is little time for feedback from higher levels to exert any influence. For moderately impaired patients, there is enough time for bottom-up and top-down activation to interact, producing lexico-semantic effects. For the more severe patients, the input to the reading system is sufficiently corrupted that it fails to effectively engage higher-order representations.

Given the slow and effortful reading performance observed in PA, one of the most striking findings is that at least some patients demonstrate a phenomenon known as "implicit recognition". Specifically, even when letter strings are presented too briefly for the patients to recognise explicitly (typically a $250 \mathrm{~ms}$ duration), these patients still perform above chance (albeit never perfectly) on tasks such as lexical decision or semantic categorisation (Coslett \& Saffran, 1989; Coslett, Saffran, Greenbaum, \& Schwartz, 1993; Doctor, Sartori, \& Saling, 1990; Feinberg, Dyckesberke, Miner, \& Roane, 1995; Lambon Ralph et al., 2004; Saffran \& Coslett, 1998; Shallice \& Saffran, 1986). Two approaches have been taken to explain this behavioural pattern. The first is that, along with the impaired word recognition system, there is an additional, righthemisphere process that can fully recognise words and access associated meaning. Because this secondary system has limited connectivity to spoken output, patients are able to recognise words and access their meaning but are unable to generate their pronunciation (Saffran \& Coslett, 1998). In contrast, the second approach suggests that this phenomenon does not constitute full word recognition but instead reflects the remaining partial activation within the damaged, standard reading system (Lambon Ralph et al., 2004). The fact that these patients never perform at perfect levels of accuracy on these two-alternative forced-choice (2AFC) lexical decision and semantic categorisation tasks is in keeping with the latter hypothesis. Furthermore, in a single-case study, Lambon Ralph et al. (2004) demonstrated that accuracy on these tasks varied: (a) with word familiarity and imageability, and the semantic specificity of the decision; (b) with ultra-familiar personal vocabulary, recognition became explicit; and (c) perhaps most importantly, when lexical decision and semantic categorisation were directly compared with $2 \mathrm{AFC}$ word identity decisions then the patient performed at exactly the same mid-point, above chance but below perfect (normal) accuracy. This partial activation account is highly compatible with the interactive activation account outlined above - and thus the same approach can also explain the influence of higher-order representations upon letter identification.

Striking as the reports of implicit recognition in PA may be, this phenomenon has not been universally observed in all patients (Howard, 1991; Patterson \& Kay, 1982; Price \& Humphreys, 1992, 1995). This could be due to many factors including variations in lesion extent, time post onset, overall strategy, willingness to guess and the test materials used (Lambon Ralph et al., 2004; Saffran \& Coslett, 1998). Another possibility, which is the focus of the present paper, is that variability in the presence of the implicit recognition effect across patients is related to the severity of the reading disorder.

We tested this hypothesis using a case-series of PA patients who varied in severity but were tested in the same way using identical materials. This case-series approach allowed us to test uniformly for the prevalence of "implicit recognition" in PA and also to estimate the function between impairment severity and the degree of "implicit recognition". Furthermore, if we are correct to link "implicit recognition" in 2AFC tasks to the interactive activation account of lexico-semantic effects in reading aloud (Behrmann, Plaut, et al., 1998), then there should also be a parallel variation in the effect of frequency and imageability upon performance.

\section{Experiment 1: semantic categorisation}

The purpose of the first experiment was to establish the presence of implicit recognition (as represented by above chance performance) in a task that requires some access to semantic information. In order to promote direct comparison, we used the same semantic categorisation (living vs. non-living) task used in previous investigations of implicit recognition in PA (Coslett \& Saffran, 1989; Saffran \& Coslett, 1998; Shallice \& Saffran, 1986). This task was administered in the same way across the case-series of patients using the instructions from Saffran and Coslett (1998). These are important because many PA patients are somewhat reluctant to make a decision to a briefly presented word (they often report seeing a "flash") but it is important to persuade them to follow their intuition. Encouraging this willingness to respond was noted to be critical by Saffran and Coslett (1998). The adoption of standard administration of the same test across the case-series allowed us to determine not only the prevalence of the effect across the group but also its relationship to the severity of the reading disorder.

\subsection{Method}

\subsubsection{Patients}

The cohort comprised 10 PA patients with overt LBL reading of varying degrees (on our reading list of 180 words, overt LBL responses were produced by every patient, with their rate ranging between $7.8 \%$ and $83.8 \%$ ). These patients were recruited from local NHS speech and language therapy services. Patients were selected if they demonstrated marked increases in naming latency as a function of letter length. All are native speakers of English who had suffered from acute brain injury. At the time of testing, all patients were at least two years post-infarct and, therefore, their reading profile was likely to have stabilised after any immediate recovery/reorganisation.

As can be seen in Table 1, the majority of the patients had damage in the occipitotemporal region as a consequence of cerebral ischemia or ablation. Scans for each patient are provided in Appendix A. Overall, neuropsychological background assessment indicated that the patients had preserved working memory and phonological processing, with only a few patients slightly impaired across the variety of tasks assessing each of these capacities (SC \& EW and RK \& EW respectively). Six patients (TS, SC, AG, EW, MS, \& AT) showed mild but measureable impairments on at least one of the receptive semantic tests, and all were somewhat impaired in picture naming suggestive of visual recognition deficit. Deficits in visual processing on at least one subtest of the VOSP (Warrington \& James, 1991) were also apparent in all patients tested bar one (RK). Notably, spelling from dictation after accurate word repetition was largely intact, with only two cases showing any impairment (TS \& EW), and was normal for all patients for nonwords.

All patients showed elevated mean reading speeds on a list of 180 words comprising 60 words of three, five and seven letters (see Appendix B). N-Watch software (Davis, 2005) was used to obtain CELEX written word form frequencies per million (Baayen, Piepenbrock, \& van Rijn, 1995), and these were matched across the three letter lengths (three letters: $76.52 \pm 96.53$; five letters: $65.93 \pm 98.27$; seven letters: $73.57 \pm 92.27$ ). Reading latencies for these words were calculated from the onset of the stimulus to the onset of the correct naming response and, therefore, encompass the time taken to identify individual letters. Calculations were derived using a voice recorder and manual analysis of reaction time data using WavePad software (NCH, Swiftsound: www.nch.com.au/wavepad). Although more laborious than using a voice key, we have found that this offline method is much more natural for patients and allows us to include more severe patients who find it hard to make a single spoken response without overt letter-by-letter reading. In short, the method maximises both the number of patients and trials that we can include in the analyses.

Fig. 1 shows the length effect for each patient in reaction times and accuracy quantified for each measure in terms of slope in Table 2. There is clearly a range of performance across the case series in terms of both RT and accuracy, and in order to take this variation into account and eliminate any potential speed-accuracy tradeoffs, we computed an inverse efficiency value to combine the two into a single measure (Röder, Kusmierek, Spence, \& Schicke, 2007). As can be seen in both Fig. 1 and Table 2, this adjusts the rank ordering of severity somewhat, and all subsequent analyses therefore use this adjusted reading speed measure as an index of severity. When considering adjusted reading speeds, two things are immediately apparent. First, all patients show a considerable influence of word length upon their performance - this effect is essentially negligible amongst healthy young adults (Weekes, 1997). Secondly, the severity of the reading disorder, whether indexed by overall reading performance or the slope of the function relating performance to word length, varies substantially across patients, allowing a good range over which to assess the impact of severity upon any implicit recognition effects observed in this group.

\subsubsection{Materials}

Stimuli were identical to those used in the original Coslett and Saffran (1989) investigation and subsequently by others (Coslett et al., 1993; Lambon Ralph et al., 2004; Saffran \& Coslett, 1998). They consisted of 25 animal names (e.g., duck), 25 words judged to be visually similar to the animal names (e.g., dust) and 25 words not visually or phonologically similar to the animal names (e.g., spaces). Visually 
Table 1

Demographic and background neuropsychological data for the ten pure alexic patients included in the current study, ordered from least to most impaired according to adjusted reading speed (RT/accuracy).

\begin{tabular}{|c|c|c|c|c|c|c|c|c|c|c|c|}
\hline & Maximum & TS & RK & JM & JW & SC & JWF & AG & EW & MS & AT \\
\hline \multicolumn{12}{|l|}{ Demographics } \\
\hline Age & - & 57 & 63 & 67 & 59 & 81 & 54 & 79 & 74 & 70 & 73 \\
\hline Sex & - & $\mathrm{M}$ & $\mathrm{M}$ & $\mathrm{M}$ & $\mathrm{M}$ & $\mathrm{M}$ & $\mathrm{F}$ & $\mathrm{M}$ & $\mathrm{F}$ & $\mathrm{F}$ & M \\
\hline Handedness & & $\mathrm{RH}$ & $\mathrm{RH}$ & RH & RH & $\mathrm{RH}$ & LH & $\mathrm{RH}$ & RH & LH & $\mathrm{RH}$ \\
\hline Years of education & - & 10 & 10 & 10 & 11 & 11 & 10 & & 10 & 10 & 10 \\
\hline \multicolumn{12}{|l|}{ Lesion information } \\
\hline Neuroimaging summary & - & $\begin{array}{l}\text { Occipito- } \\
\text { temporal }\end{array}$ & $\begin{array}{l}\text { Posterior- } \\
\text { parietal }\end{array}$ & $\begin{array}{l}\text { Occipito- } \\
\text { temporal }\end{array}$ & $\begin{array}{l}\text { Occipito- } \\
\text { temporal }\end{array}$ & $\begin{array}{l}\text { Occipito- } \\
\text { temporal }\end{array}$ & $\begin{array}{l}\text { Occipito- } \\
\text { temporal }\end{array}$ & $\begin{array}{l}\text { Occipito- } \\
\text { temporo- } \\
\text { parietal }\end{array}$ & $\begin{array}{l}\text { Occipito- } \\
\text { temporo- } \\
\text { parietal }\end{array}$ & $\begin{array}{l}\text { Occipito- } \\
\text { temporal }\end{array}$ & $\begin{array}{l}\text { Occipito- } \\
\text { parietal }\end{array}$ \\
\hline Aetiology & - & $\begin{array}{l}\text { PCA } \\
\text { tumour } \\
\text { resection }\end{array}$ & MCA & $\begin{array}{l}\text { PCA } \\
\text { tumour } \\
\text { resection }\end{array}$ & PCA & PCA & $\begin{array}{l}\text { Post } \\
\text { aneurism } \\
\text { PCA infarct }\end{array}$ & PCA & MCA & PCA & PCA \\
\hline \multicolumn{12}{|l|}{ Working memory } \\
\hline \multicolumn{12}{|l|}{ Digit span } \\
\hline Forward(12) & - & 8 & NT & 12 & 7 & 4 & 6 & 8 & 4 & 10 & 7 \\
\hline Backward(12) & - & 4 & NT & 7 & 4 & 2 & 5 & 4 & 2 & 8 & 6 \\
\hline \multicolumn{12}{|l|}{ Visual processing } \\
\hline Diagnosis $^{*}$ & - & Hemianopia & Hemianopia & $\begin{array}{l}\text { Upper } \\
\text { quadrant }\end{array}$ & Hemianopia & Hemianopia & Hemianopia & Hemianopia & Hemianopia & Hemianopia & $\begin{array}{l}\text { Upper } \\
\text { quadrant }\end{array}$ \\
\hline \multicolumn{12}{|l|}{ VOSP } \\
\hline Incomplete letters & 20 & 19 & 20 & 20 & 19 & 18 & 17 & 19 & 19 & 16 & 16 \\
\hline Silhouettes & 30 & 22 & 20 & 18 & 25 & 3 & 24 & 15 & 12 & 19 & 13 \\
\hline Object decision & 20 & 18 & 15 & 17 & 17 & 14 & 19 & 10 & 17 & 16 & 17 \\
\hline Progressive silhouettes & 20 & 5 & 20 & 11 & 8 & NT & NT & 16 & 12 & 9 & 9 \\
\hline Dot counting & 10 & 10 & 10 & 10 & 10 & 10 & 10 & 10 & 10 & 9 & 10 \\
\hline Position discrimination & 20 & 18 & 20 & 20 & 20 & 17 & 16 & 19 & 20 & 19 & 20 \\
\hline Number location & 10 & 10 & 9 & 10 & 10 & 10 & 8 & 9 & 10 & 10 & 9 \\
\hline Cube analysis & 10 & 10 & 6 & 10 & 9 & 9 & 10 & 4 & 7 & 7 & 10 \\
\hline \multicolumn{12}{|l|}{ Spelling from dictation } \\
\hline PALPA 40: Words & 40 & 12 & NT & 30 & 33 & NT & 32 & NT & 12 & 33 & NT \\
\hline PALPA 45: Nonwords & 24 & 19 & NT & 21 & 19 & NT & 24 & NT & 15 & 21 & NT \\
\hline \multicolumn{12}{|l|}{ Semantic processing } \\
\hline Naming ${ }^{\dagger}$ & 64 & 40 & 52 & 60 & 59 & 59 & 54 & NT & 45 & 45 & 54 \\
\hline Camel and cactus (pictures) ${ }^{\dagger}$ & 64 & 24 & 52 & 61 & 52 & $\begin{array}{l}51 / 52 \\
\text { PPT }\end{array}$ & 61 & 43/52 PPT & 45 & 47 & $\begin{array}{l}\text { 44/52 } \\
\text { PPT }\end{array}$ \\
\hline Spoken word to picture matching ${ }^{\dagger}$ & 64 & 63 & NT & 63 & 64 & 62 & NT & NT & 57 & 62 & 63 \\
\hline 96 Synonyms & 96 & 83 & 90 & 93 & 93 & 71 & 94 & NT & 76 & 81 & NT \\
\hline \multicolumn{12}{|l|}{ Phonological processing } \\
\hline \multicolumn{12}{|l|}{ PALPA 2: Phonological judgement } \\
\hline Total & 72 & 68 & 72 & 72 & 71 & NT & 72 & NT & 65 & 71 & NT \\
\hline Same & 36 & 36 & 36 & 36 & 36 & NT & 36 & NT & 34 & 36 & NT \\
\hline Different & 36 & 32 & 36 & 36 & 35 & NT & 36 & NT & 31 & 35 & NT \\
\hline PALPA 15: Rhyme judgement & 60 & 56 & 57 & 56 & 57 & NT & 58 & NT & 56 & 53 & NT \\
\hline \multicolumn{12}{|l|}{ Phonological segmentation ${ }^{\dagger \dagger}$} \\
\hline Total & 96 & 87 & 73 & 94 & 96 & NT & 96 & NT & 69 & 91 & NT \\
\hline Addition & 48 & 48 & 36 & 46 & 48 & NT & 48 & NT & 28 & 45 & NT \\
\hline Subtraction & 48 & 39 & 37 & 48 & 48 & NT & 48 & NT & 41 & 46 & NT \\
\hline
\end{tabular}

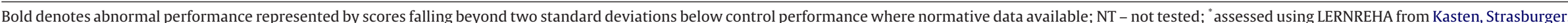

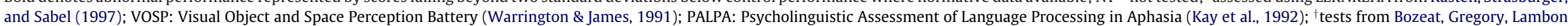
Ralph, and Hodges (2000); †t tests from Patterson and Marcel (1992); PPT: Pyramids and Palm Trees Test (Howard \& Patterson, 1992). 

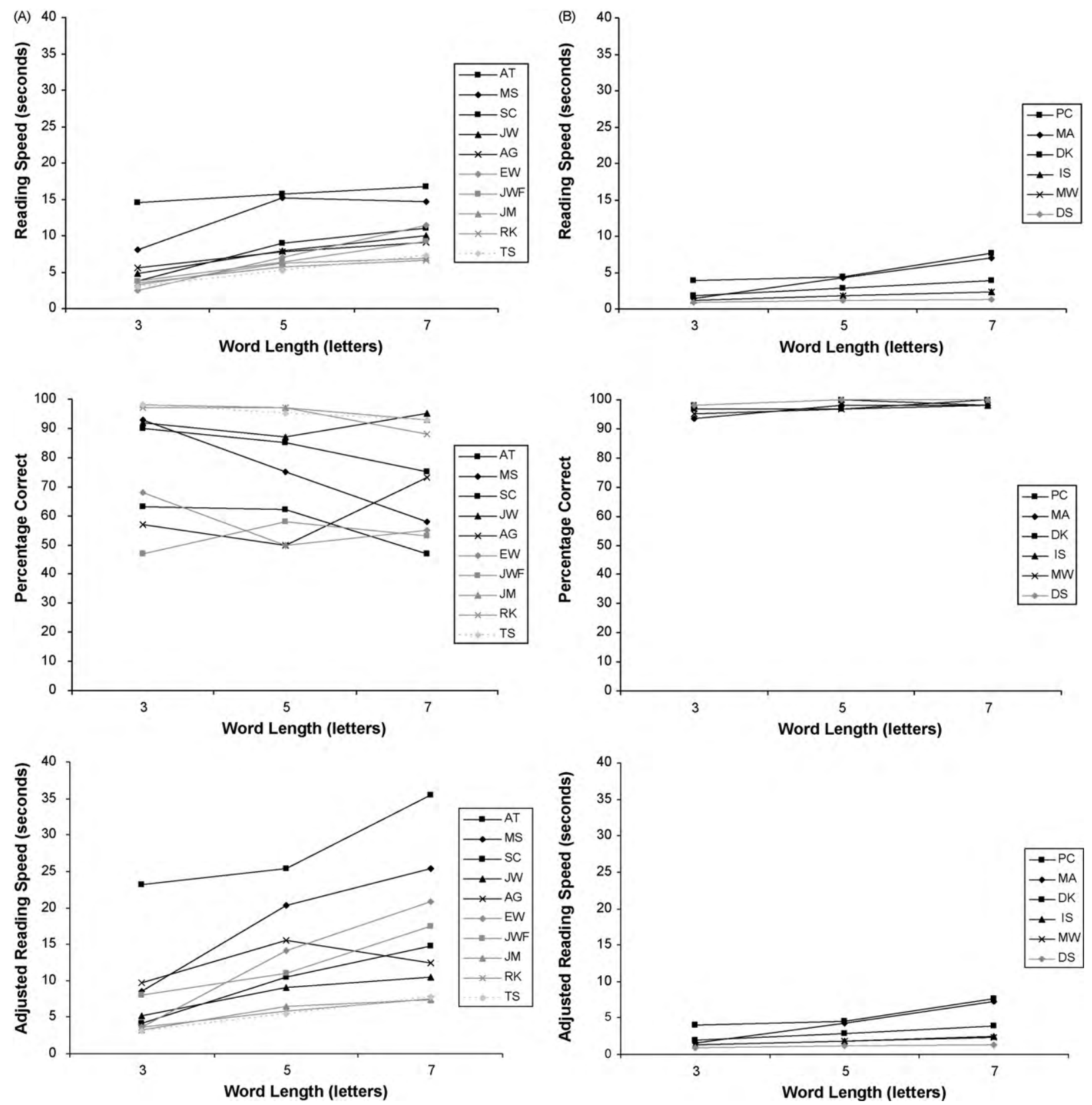

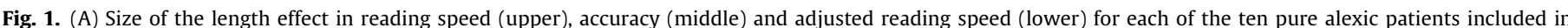

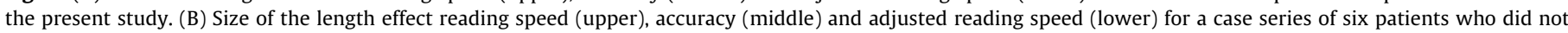

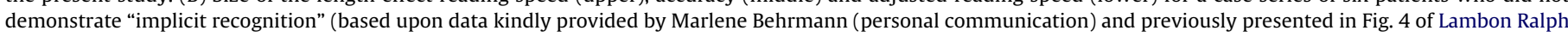

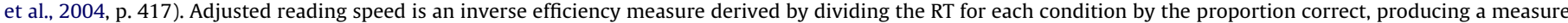
comparable to reaction time but corrected for variations in accuracy (as per Röder, Kusmierek, Spence, \& Schicke, 2007).

similar foils shared at least the first two letters with the matched animal name. The three types of stimuli were also matched for frequency [mean frequencies counts per million $( \pm S D)$ : animal names $(12.6 \pm 23.58)$, visually similar foils $(13.56 \pm 22.1)$ and unrelated foils (12.72 \pm 23.93$)$ : (Kucera \& Francis, 1967)]. Animal names and foils differed in length by no more than one letter [mean letter length: animal names $(5.96 \pm 1)$, visually similar foils $(5.92 \pm 0.9)$ and unrelated foils $(5.96 \pm 1)$ ]. All stimuli were presented in black, Arial 36 point font on a white background, subtending a vertical visual angle of 1.15 degrees per letter ( 1.48 degrees in the case of letters with an ascender or descender).

\subsubsection{Procedure}

The patients were asked to decide whether a presented word was the name of a living or non-living thing. Stimulus presentation was controlled using E-prime software (Schneider, Eschman, \& Zuccolotto, 2002) on a laptop. Each trial was initiated by the experimenter after the participant indicated his or her readiness. A fixation point was presented for $1000 \mathrm{~ms}$ before being replaced by the target word. Following the method used for the vast majority of patients reported previously by
Saffran, Coslett and colleagues, we used a duration of $250 \mathrm{~ms}$. This was short enough to prevent explicit identification, given that the fastest reading speed for three letter words for any patient exceeded $2000 \mathrm{~ms}$. Patients were asked to report verbally whether the presented word referred to a "living" or "non-living" entity. Their first response was recorded by the experimenter. Patients were also asked to tell the experimenter if they could read the word presented on any given trial and any such explicitly identified items were excluded from analysis.

\subsection{Results}

The patients' results are summarised in Table 3, which includes the rate of discarded trials where patients explicitly identified the target item. Binomial tests on overall accuracy revealed that performance of 8 out of 10 patients was significantly better than would be expected by chance (binomial $p<0.032$, one-tailed), with other two patients (AG and JW) showing a marginally significant difference (binomia $p<0.085$, one-tailed). In terms of the relationship between "implicit recognition" and reading severity, we found that overall accuracy was significantly negatively 
Table 2

Slopes reflecting the length effect in mean reading speed, accuracy, and adjusted reading speed for each of the ten pure alexic patients included in the present study, ordered from most to least impaired according to adjusted reading speed (RT/accuracy).

\begin{tabular}{llrl}
\hline Patient & Reading speed & \%Accuracy & Adjusted reading speed \\
\hline AT & 0.523 & -4.000 & 3.085 \\
MS & 3.290 & 1.728 & 1.087 \\
SC & 0.878 & 0.427 & 0.620 \\
JW & 0.687 & -0.286 & 0.507 \\
AG & 0.682 & 2.724 & 0.712 \\
EW & 2.497 & 0.040 & 1.738 \\
JWF & 0.608 & -0.581 & 0.524 \\
JM & 0.658 & -0.115 & 0.387 \\
RK & 0.809 & 1.929 & 0.890 \\
TS & 1.294 & 0.389 & 1.203 \\
Average & 1.193 & 0.225 & 1.075 \\
\hline
\end{tabular}

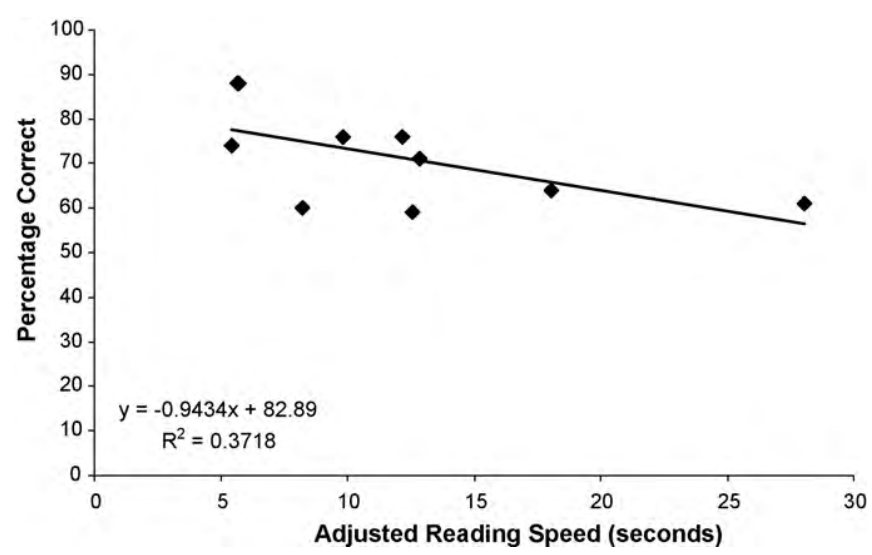

Fig. 2. Relationship between overall accuracy in the semantic categorisation task and severity of the reading disorder.

correlated with severity of the reading disorder $\left(r_{\mathrm{s}}=.-555, p=.048\right.$, one-tailed), as displayed in Fig. 2. As can be seen in Fig. 3 however, performance was not equally good across all conditions, such that amongst the non-living trials, the visually related foils were more likely to be erroneously accepted than the unrelated foils $(t(9)=-3.83, p=.002$, one-tailed)

\subsection{Discussion}

This experiment showed that the majority of these patients were able to derive enough semantic information to allow categorisation as living or non-living entities at a level of accuracy significantly above chance. This occurred despite the fact that, given the limited duration of $250 \mathrm{~ms}$, these patients were rarely able to identify the items explicitly. As well as measuring the prevalence of "implicit recognition" in a PA case series, we were also interested in assessing its relationship to reading severity. Overall accuracy was found to be negatively correlated with the severity of the reading disorder, such that the most impaired readers were the least accurate in the semantic categorisation task. As highlighted in the introduction, it should be noted that although performing above chance levels, none of these patients - like those reported in the existing literature - got close to perfect performance in this simple semantic categorisation task (which requires a $2 \mathrm{AFC}$, domain level discrimination). It seems unlikely that this constitutes strong evidence for the notion that the patients were uniquely indentifying each word, albeit implicitly. Instead, this intermediate

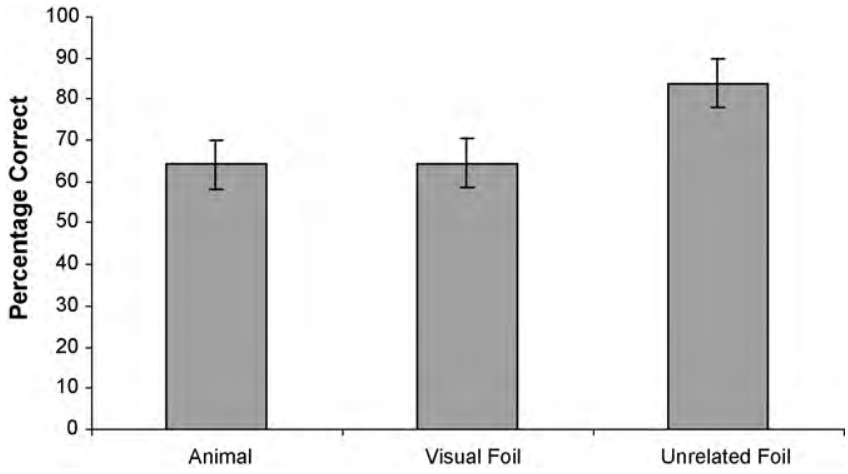

Fig. 3. Group average performance in the semantic categorisation task according to condition. Error bars show standard error.

level of performance seems more consistent with the partial activation account. In keeping with this second hypothesis, we found that the patients' accuracy was significantly lower for the visually-similar than unrelated foils. If the patients were uniquely indentifying each target item then it should have been possible for them to discriminate irrespective of foil type. The result does fit with the partial activation account: partial activation within the remaining reading system should be sufficient to bias 2AFC semantic decisions above chance (but not to perfect performance) but performance should be much weaker when foils and targets are visually related because there is insufficient remaining activation to drive their discrimination.

\section{Experiment 2: lexical decision}

In addition to semantic categorisation, lexical decision has often been used to assess "implicit recognition". Again the current literature indicates that the presence of this phenomena varies across patients (Behrmann, Plaut, et al., 1998). Accordingly, we assessed the same patient case-series on a lexical decision task under limited exposure durations in order to test if the same prevalence and relationship with severity arose. In addition to this replication aim of Experiment 2, the lexical decision task also licensed an exploration of the impact of two lexico-semantic variables upon accuracy. Word frequency has been found to affect the performance of PA patients, not only in terms of reading speeds with unlimited exposure (Behrmann, Plaut, et al., 1998), but also in terms of discrimination accuracy at the limited exposure durations used for assessing "implicit recognition" (Coslett \& Saffran, 1994; Lambon Ralph et al., 2004). In this experiment, therefore, we assessed the relationship between the size of the frequency effect and severity of the reading disorder.

The influence of the semantic variable, imageability, has also been shown to affect reading aloud performance in at least some PA cases (Behrmann, Plaut, et al., 1998). To our knowledge, there has been only one previous single-case study report of an impact of this factor on limited exposure lexical decision performance (Lambon Ralph et al., 2004). We also included, therefore, an imageability manipulation in the current task, allowing us to index the extent to which semantic activation may be harnessed to inform lexical decision. Given the results from the semantic categorisation experiment, we would expect to obtain imageability effects in this lexical decision task, although the magnitude of the effect may vary with severity of the reading disorder.

\subsection{Method}

\subsubsection{Patients}

Nine of the ten PA patients described in Experiment 1, completed this lexical decision task (one patient, EW, was no longer available for testing).

\subsubsection{Materials}

Items were selected from PALPA test number 25 (Kay, Lesser, \& Coltheart, 1992) which orthogonally varies both frequency and imageability, and pairs each word

Table 3

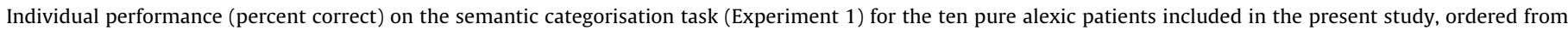
least to most impaired according to adjusted reading speed (RT/accuracy).

\begin{tabular}{|c|c|c|c|c|c|c|c|c|c|c|}
\hline Target & TS & RK & JM & JW & SC & JWF & AG & EW & MS & AT \\
\hline Animal & 77 & 92 & 84 & 33 & 88 & 68 & 48 & 56 & 48 & 48 \\
\hline Visual foil & 52 & 72 & 80 & 63 & 54 & 64 & 56 & 76 & 76 & 52 \\
\hline Unrelated foil & 92 & 100 & 100 & 63 & 84 & 96 & 72 & 80 & 68 & 84 \\
\hline Overall & $74^{*}$ & $88^{*}$ & $88^{*}$ & 60 & $76^{*}$ & $76^{*}$ & 59 & $71^{*}$ & $64^{*}$ & $61^{*}$ \\
\hline$\%$ of excluded trials & 9.3 & 0 & 0 & 18.6 & 1.3 & 0 & 0 & 0 & 0 & 0 \\
\hline
\end{tabular}

* Performance was significantly above that expected by chance. 
Table 4

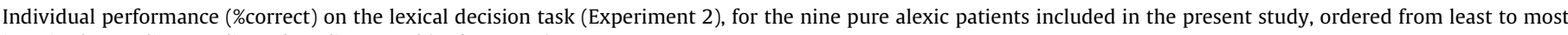
impaired according to adjusted reading speed (RT/accuracy).

\begin{tabular}{|c|c|c|c|c|c|c|c|c|c|}
\hline Target & TS & RK & JM & JW & SC & JWF & AG & MS & AT \\
\hline HF HI & 78 & 87 & 87 & 77 & 100 & 87 & 60 & 50 & 87 \\
\hline HF LI & 40 & 87 & 87 & 67 & 80 & 67 & 60 & 53 & 27 \\
\hline LF HI & 64 & 100 & 87 & 64 & 100 & 80 & 67 & 47 & 73 \\
\hline LF LI & 40 & 87 & 60 & 33 & 73 & 60 & 73 & 67 & 60 \\
\hline All words & 52 & 90 & 80 & 59 & 88 & 73 & 65 & 54 & 62 \\
\hline Nonwords & 72 & 47 & 88 & 63 & 37 & 75 & 29 & 63 & 45 \\
\hline Overall & $63^{*}$ & $68^{*}$ & $84^{*}$ & $61^{*}$ & $63^{*}$ & $74^{*}$ & 47 & $58^{*}$ & 53 \\
\hline$\%$ of excluded trials & 8.3 & 0 & 0.8 & 10 & 0.8 & 0 & 0 & 1.7 & 0 \\
\hline
\end{tabular}

$\mathrm{HF}=$ high frequency, $\mathrm{LF}=$ low frequency, $\mathrm{HI}$ = high imageability, $\mathrm{LI}=$ low imageability

* Performance was significantly better than that expected by chance.

with a pronounceable nonword. In total there are 60 words ( 15 for each combination of imageability and frequency) and 60 nonwords.

\subsubsection{Procedure}

The procedure used for stimulus display and presentation was identical to that in Experiment 1, with the exception that the patients were asked to decide whether the item presented was a word or a nonword.

\subsection{Results}

The results for each patient are summarised in Table 4, which includes the rate of discarded trials for each patient. Binomial tests on overall accuracy revealed that 7 out of 9 patients performed better than expected by chance (binomial $p<0.041$, one-tailed), with the two remaining patients (AG and AT) performing at chance levels (binomial $p>0.262$, one-tailed). In terms of the extent to which task performance was related to reading severity, we again found that overall accuracy was significantly negatively correlated with severity of the reading disorder $\left(r_{\mathrm{s}}=-.636\right.$, $p=.033$, one-tailed), as displayed in Fig. 4 .

As can be seen in Fig. 5, performance for the group was affected more strongly by imageability than frequency. Word responses were analysed by a within-participants 2 (frequency) $\times 2$ (imageability) ANOVA that included severity as a continuous predictor. The results revealed a significant two-way interaction between frequency and imageability $(F(1,7)=10.92, M S E=471.09, p=.013)$ that was qualified by a significant three-way interaction with severity $(F(1,7)=16.65$, $M S E=719.74, p=.005$ ). The nature of this interaction can be seen in Fig. 6 . Specifically, the size of the frequency effect was negatively related to severity but only for the low-imageability words $\left(r_{s}=-.571, p=.054\right.$, one-tailed) and not high-imageability words $\left(r_{\mathrm{s}}=.134, p=.365\right.$, one-tailed). Similarly, the size of the imageability effect was negatively related to severity but only for low-frequency words $\left(r_{\mathrm{s}}=-.546, p=.064\right.$, one-tailed $)$ and not for high-frequency words $\left(r_{\mathrm{s}}=-.009\right.$, $p=.491$, one-tailed).

\subsection{Discussion}

As with semantic categorisation (Experiment 1), we found that the majority of these PA patients performed at above chance levels when making lexical decisions. This occurred despite the fact that most patients were rarely able to identify the items explicitly and any trials in which they did so were excluded from the anal-

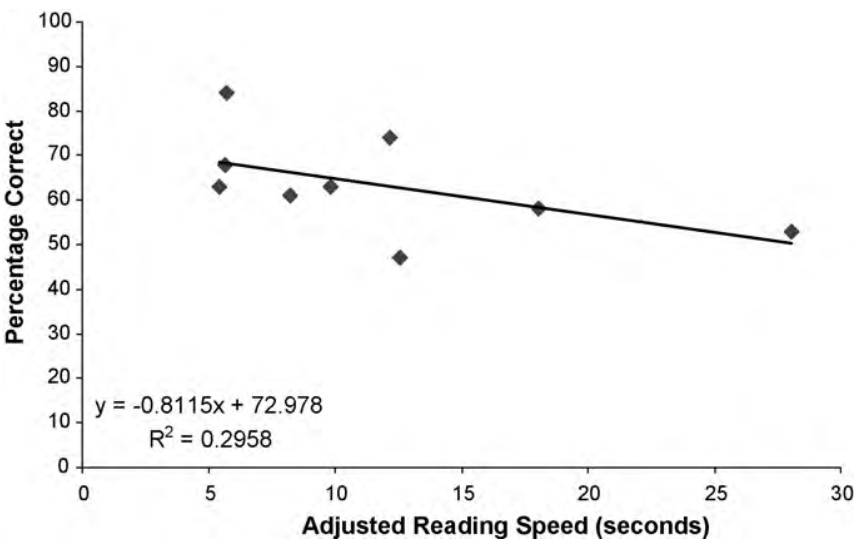

Fig. 4. Relationship between overall accuracy in the lexical decision task and severity of the reading disorder.

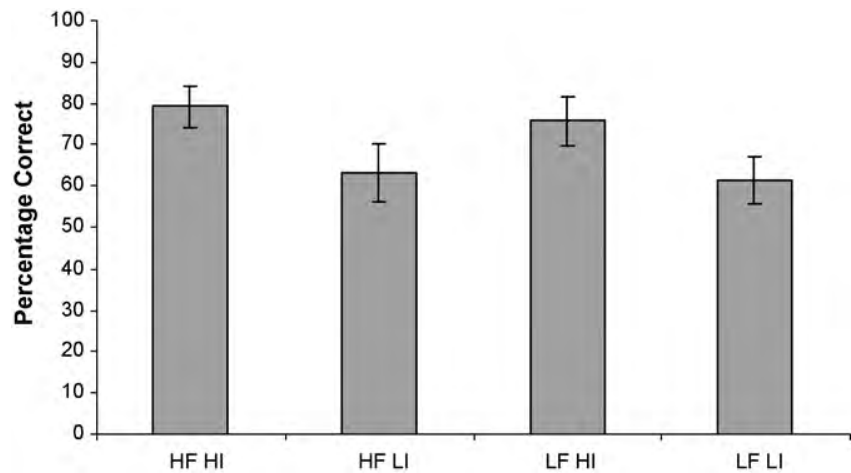

Fig. 5. Group average performance in the lexical decision task according to condition. Error bars show standard error.

(A)

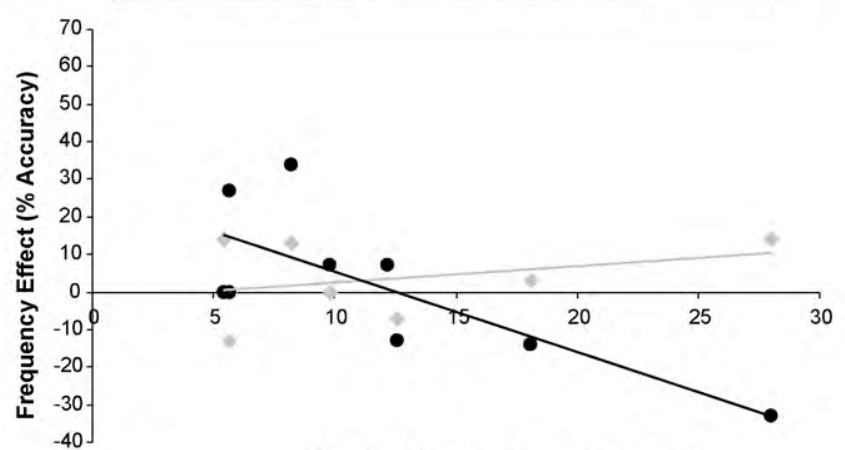

Adjusted Reading Speed (seconds)

(B) High Frequency $\bullet$ Low Frequency — Linear (High Frequency) — Linear (Low Frequency)

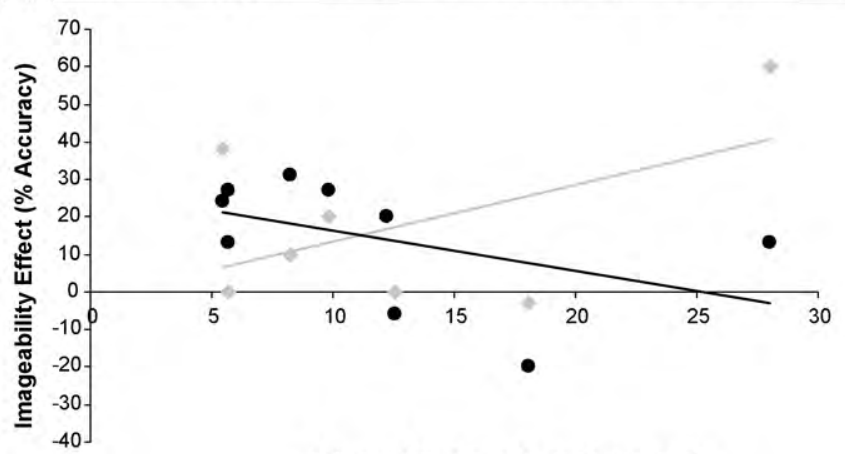

Adjusted Reading Speed (seconds)

Fig. 6. Relationship between reading severity and (A) the size of the frequency effect; (B) the size of the imageability effect. Regression lines shown in black indicate a significant relationship. 
ysis. Again we found that overall accuracy was negatively correlated with reading severity, such that the more impaired readers tended to be less accurate in the lexical decision task. Consistent with interactive accounts of word recognition in PA (Behrmann, Plaut, \& Nelson, 1998), we found the patients' accuracy for words exhibited an interaction between frequency and imageability, and that this was related to the severity of their reading disorder. Specifically, for low-imageability words, the frequency effect diminished with increasing severity. Similarly, for low-frequency words, the imageability effect diminished with increasing severity.

\section{General discussion}

Using a case-series approach, the present experiments demonstrated further evidence for "implicit recognition" in a group of PA patients, who varied considerably in the overall severity of their reading disorder. In both semantic categorisation and lexical decision, the majority of patients performed significantly above chance even though the exposure duration $(250 \mathrm{~ms})$ was too short for explicit recognition (the fastest reading aloud responses in our case-series were around $2 \mathrm{~s}$ ). The strength of this "implicit recognition" was negatively related to reading severity, such that the more severely impaired patients showed the lowest accuracy. By including a manipulation of imageability within the lexical decision task, we were also able to assess the impact of semantic representations upon "implicit recognition" in lexical decision amongst a case series of PA patients for the first time. Consistent with results from a previous single-case study (Lambon Ralph et al., 2004), we found that accuracy was influenced by frequency and imageability. Furthermore, we found that these effects were modulated by reading severity, with the largest effects of these lexico-semantic variables exhibited by the mildest patients within this case series.

Two general explanations for higher-order effects in PA reading, including "implicit recognition" have been proposed. The multiple systems approach (Buxbaum \& Coslett, 1996; Coslett \& Saffran, 1989; Coslett et al., 1993; Saffran \& Coslett, 1998) suggests that PA reading is underpinned by a combination of the impaired left-hemisphere reading system plus an intact right-hemisphere word recognition mechanism (which can map from orthography to semantics but is unable to generate pronunciations). The partial activation account (Behrmann, Plaut, et al., 1998; Lambon Ralph et al., 2004) argues that PA performance reflects the remaining activation within the single, damaged reading system. We argue that the results presented here, as well as evidence for top-down effects in PA reading (Behrmann, Plaut, et al., 1998), are highly consistent with the partial activation account. Furthermore, this proposal provides a potential explanation for why some PA patients demonstrate "implicit recognition" effects and many others do not (Behrmann, Plaut, et al., 1998; Howard, 1991; Patterson \& Kay, 1982).

The "implicit recognition" behaviour observed in the majority of the patients reported in this study is representative of those noted in previous reports. The term "implicit recognition" could be taken to imply that although patients fully and uniquely recognise written words and are able to activate the full, associated word meaning, yet cannot indicate the identity of the word by naming it. As far as we are aware, this absolute dissociation has never been reported. Instead, the behavioural phenomenon is much more graded in various ways: (a) nature of task - "implicit recognition" is always measured using a forced-choice paradigm and "explicit recognition" by unique identification; (b) level of performance - by definition, accuracy is significantly above chance but is considerably below perfect performance even for broad distinctions such as domain-level differentiation; and (c) variation of accuracy - this mid-range performance can be modulated by various task and stimulus parameters including the number of choices, foil competitiveness, familiarity, frequency and image- ability, etc. (cf. results presented in this study plus Saffran and Coslett (1998) and Lambon Ralph et al. (2004)). All three aspects are consistent with partial activation as this will boost discrimination to above chance in forced-choice judgement tests but will not produce perfect performance. Furthermore, this partial activation will be more effective in the simpler tasks (e.g., with the smallest number of choices and easiest foils) and for the most robustly represented words (e.g., most frequent/familiar and highest in imageability).

Other studies have investigated another form of higher order activation in PA, finding influences of lexico-semantic variables like frequency and imageability upon standard (exposure duration unlimited) reading times (Behrmann, Plaut, et al., 1998). Again these are consistent with the partial activation account, in which orthographic activation cascades forward ultimately to semantic representations that are then able, through feedback, to influence earlier letter-level activation (as per interactive activation models of word recognition (Behrmann, Plaut, et al., 1998; Lambon Ralph et al., 2004)). Critically, in cascaded interactive activation models, activation can percolate though the system even if it is insufficient to identify the target word uniquely. In a step towards linking "implicit recognition" and lexico-semantic influences, we explored the impact of imageability upon accuracy in limited exposure lexical decision. Although this effect had been observed in a single-case study (Lambon Ralph et al., 2004) it had not been explored before in a case series of PA patients. The partial activation account would expect accuracy to be greatest for words with the richest (i.e., concrete) semantic representations because these concepts will generate the greatest degree of semantic feedback to earlier orthographic levels. Under this hypothesis, one would also expect the size of imageability effects to parallel the degree of activation remaining within the damaged reading system; the more activation percolating, the greater the influence of lexico-semantic variables. This is exactly the pattern we found in the current PA case-series.

One conundrum within the PA literature is why some patients demonstrate "implicit recognition" and others do not (Behrmann, Plaut, et al., 1998; Lambon Ralph et al., 2004). We believe that the findings from the present case-series study, when combined with two previous observations, provide a potential, systematic solution. This is based on the assumption that there is an inverted " $U$ shaped" function that relates reading severity to the magnitude of lexico-semantic effects (Behrmann, Plaut, et al., 1998) and "implicit recognition" (Lambon Ralph et al., 2004). As noted in the introduction, this idea assumes that normal participants and patients with mild impairments show little influence of higher order variables because the orthographic, bottom-up input is so strong and accurate that unique identification is achieved rapidly. With moderate levels of impairment, identification is slower and more errorful but there is still sufficient activation to engage higher-order representations, which can feedback and thus boost word recognition. In the limit, however, the remaining input activation within a heavily damaged reading system is so weak that it is unable to generate appreciable interactive activation. The second observation is that PA patients with "implicit recognition" tend to have more severe reading deficits overall (see Fig. 4 of Lambon Ralph et al. (2004)). Following this previous study, Fig. 1B re-plots the basic timed reading data from a case series of patients without "implicit recognition" effects (Behrmann, personal communication), so that they can be directly compared to the background reading results of the present case-series. The reading behaviour of five of these six patients has been reported in Behrmann, Nelson, et al. (1998), with the other patient, PC, considered in Behrmann, Shomstein, Black, and Barton (2001). The reading abilities of these patients were assessed with a 60-item list of 3,5 and 7 letter words (see Behrmann, Plaut, et al., 1998). Their implicit recognition abilities were assessed 
using limited display duration semantic categorisation and lexical decision tasks comparable, but not identical, to those we used here.

When we compare the reading performance of the current case series with the pure alexic patients who did not show "implicit recognition" as displayed in Fig. 1, we see that whilst there was considerable variation in the reading times of our PA patients, all of them had slower reading times and/or lower reading accuracy than those in the Behrmann case series. Additionally, we found that "implicit recognition" and imageability effects reduced in line with reading severity across our PA case-series. These elements and observations fit closely with the hypothesised inverted "U-shaped" severity function. PA patients with relatively fast recognition times, are simply too mild to demonstrate "implicit recognition" (on the up-slope of the inverted U-shaped function). In contrast, our caseseries would appear to have sampled the peak and/or down-slope of this function. In sum, these results indicate that there are, in fact, two reasons why PA patients might not demonstrate "implicit recognition": their reading disorder is either too mild, or too severe.

We finish by considering the alternative, two-systems hypothesis (Buxbaum \& Coslett, 1996; Coslett \& Saffran, 1989; Coslett et al., 1993; Saffran \& Coslett, 1998). According to this view, "implicit recognition" results from the use of an undamaged righthemisphere reading system. Given the array of partial-recognition effects reviewed above, it might be possible to capture these by assuming that this secondary reading system is relatively impoverished and inefficient. Most versions of this hypothesis seem to assume that the right-hemisphere system replicates whole-word recognition mechanisms up to and including semantic representations (Coslett \& Saffran, 1989) and, as such, we might expect to see evidence of uniquely-identifying yet implicit word recognition which we do not. It should be noted, however, that recent evidence in support of this proposal has been provided by neuroimaging studies demonstrating increased activation in the right posterior fusiform region amongst PA patients who display an explicit LBL strategy relative to normal readers (Cohen \& Dehaene, 2004; Cohen et al., 2003). In contrast, Pyun, Sohn, Jung, and Nam (2007) used serial fMRI in a PA patient to demonstrate that the increased activation of the right posterior fusiform corresponded to increased proficiency in application of the LBL strategy (although see Henry et al. (2005) for a contrasting result). The study of Pyun et al. (2007) suggests that it may be the right rather than left hemisphere that is responsible for the explicit serial processing seen in $\mathrm{PA}$, in contrast to the two-systems account. This is consistent with the finding that transcranial magnetic stimulation of the right but not the left hemisphere disrupted the performance of a recovered PA patient (Coslett \& Monsul, 1994). Future studies that combine functional imaging with detailed neuropsychological exploration of a case series of PA patients will be required to reveal the neural basis of partial whole word activation and letter-by-letter strategies.

\section{Acknowledgements}

We are extremely grateful to Dr Diana Caine for helpful discussions of the PA patients reported in this paper, and to Professor Marlene Behrmann for access to data from her PA patients.

\section{Appendix A.}

Structural scans for all patients in the present study showing lesion area. Patients are ordered from mildest to most severe according to the inverse efficiency measure of reading aloud.
(A) Patient TS

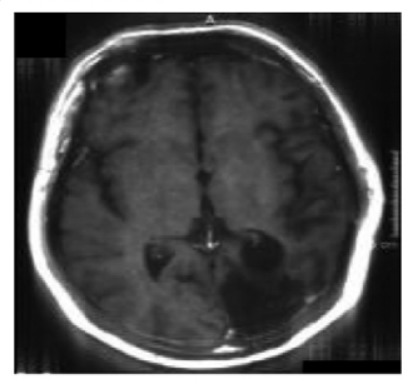

Patient JM

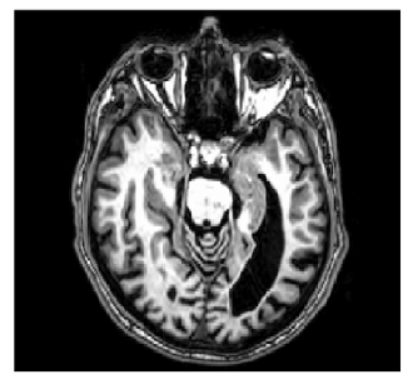

Patient SC

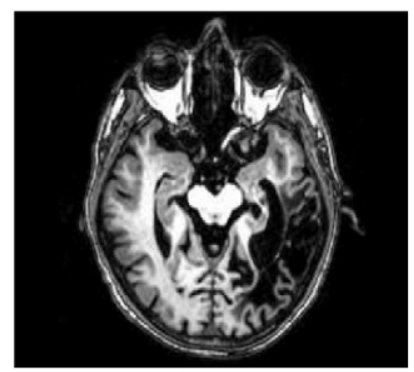

Patient AG

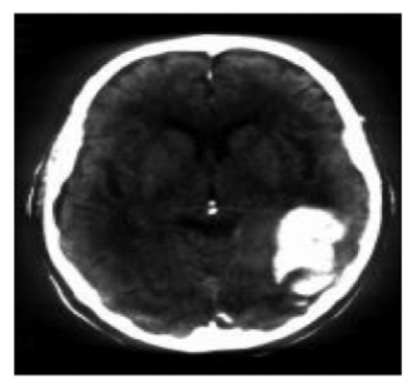

Patient MS

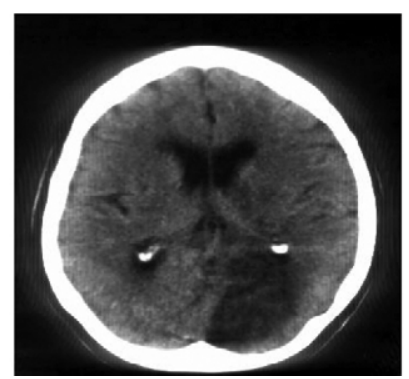

Patient RK

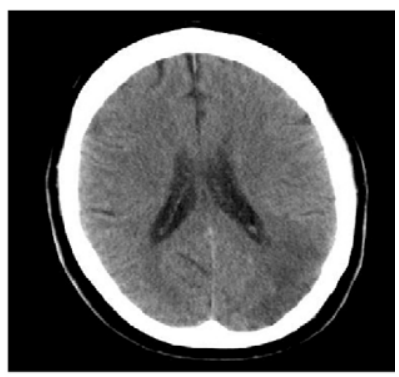

Patient JW

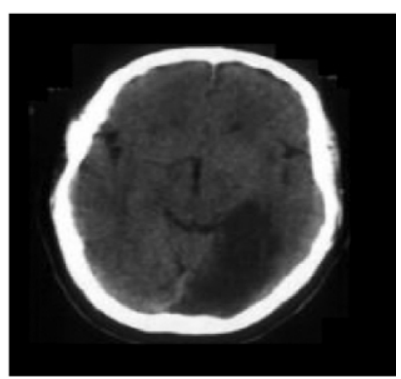

Patient JWF

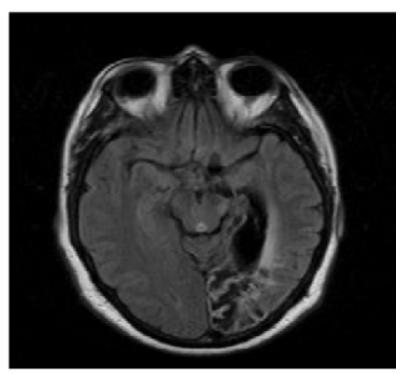

Patient EW

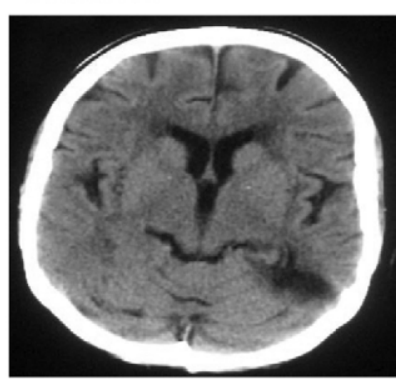

Patient AT

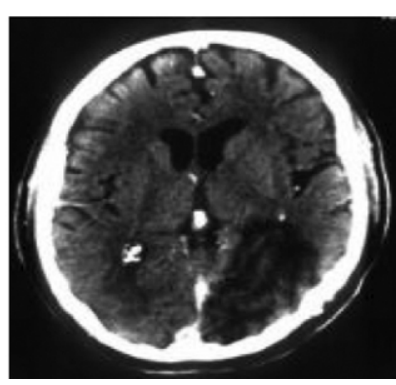

Appendix B.

List of the three, five and seven letter words used to assess each patient's reading aloud. 


\begin{tabular}{|c|c|c|}
\hline age & check & benefit \\
\hline god & style & hundred \\
\hline eye & judge & special \\
\hline fit & field & student \\
\hline $\operatorname{tax}$ & image & teacher \\
\hline bad & carry & society \\
\hline bar & stare & purpose \\
\hline hit & raise & account \\
\hline cry & dance & picture \\
\hline leg & piece & silence \\
\hline sea & house & contact \\
\hline bit & sense & support \\
\hline set & paint & mention \\
\hline $\operatorname{dog}$ & cover & company \\
\hline law & price & measure \\
\hline oil & stick & control \\
\hline son & shape & problem \\
\hline sir & level & freedom \\
\hline fly & music & surface \\
\hline box & worst & country \\
\hline air & force & council \\
\hline act & sound & concern \\
\hline win & class & service \\
\hline tie & heavy & english \\
\hline buy & heart & village \\
\hline job & table & general \\
\hline red & count & million \\
\hline bed & cause & quality \\
\hline gun & above & present \\
\hline ten & build & kitchen \\
\hline zen & resin & steeple \\
\hline sty & scone & insulin \\
\hline jib & squaw & pendant \\
\hline tot & vinyl & probate \\
\hline lug & clout & persona \\
\hline bib & frisk & console \\
\hline cud & scree & linseed \\
\hline pip & alloy & acrobat \\
\hline doe & ether & messiah \\
\hline oar & tepee & martian \\
\hline hag & venom & typhoid \\
\hline roe & pansy & memento \\
\hline spa & spook & lacquer \\
\hline pox & alder & brewery \\
\hline cam & titan & cleaver \\
\hline $\operatorname{cog}$ & spore & hammock \\
\hline yар & wafer & treacle \\
\hline gem & acorn & fluster \\
\hline amp & toxin & flotsam \\
\hline nil & shard & blemish \\
\hline elk & slush & granule \\
\hline pun & prank & stardom \\
\hline raj & nomad & ferment \\
\hline yen & capon & mercury \\
\hline oat & sable & bequest \\
\hline ewe & swill & proverb \\
\hline imp & hazel & stealth \\
\hline yew & glade & gazelle \\
\hline gel & vowel & freckle \\
\hline bop & smock & venison \\
\hline
\end{tabular}

\section{References}

Arguin, M., \& Bub, D. N. (1993). Single-character processing in a case of pure alexia. Neuropsychologia, 31(5), 435-458.

Baayen, R. H., Piepenbrock, R., \& van Rijn, H. (1995). The CELEX lexical database. Release 2: [CD-ROM]. Philadelphia: Linguistic Data Consortium, University of Pennsylvania.

Behrmann, M., Nelson, J., \& Sekuler, E. B. (1998). Visual complexity in letter-by-letter reading: "Pure" alexia is not pure. Neuropsychologia, 36(11), 1115-1132.

Behrmann, M., Plaut, D. C., \& Nelson, J. (1998). A literature review and new data supporting an interactive account of letter-by-letter reading. Cognitive Neuropsychology, 15(1-2), 7-51.

Behrmann, M., \& Shallice, T. (1995). Pure alexia-A nonspatial visual disorder affecting letter activation. Cognitive Neuropsychology, 12(4), 409-454.

Behrmann, M., Shomstein, S. S., Black, S. E., \& Barton, J. J. S. (2001). The eye movements of pure alexic patients during reading and nonreading tasks. Neuropsychologia, 39(9), 983-1002.
Bozeat, S., Gregory, C. A., Lambon Ralph, M. A., \& Hodges, J. R. (2000). Which neuropsychiatric and behavioural features distinguish frontal and temporal variants of frontotemporal dementia from Alzheimer's disease? Journal of Neurology Neurosurgery and Psychiatry, 69(2), 178-186.

Bub, D. N., \& Arguin, M. (1995). Visual word activation in pure alexia. Brain and Language, 49(1), 77-103.

Buxbaum, L. J., \& Coslett, H. B. (1996). Deep dyslexic phenomena in a letter-by-letter reader. Brain and Language, 54(1), 136-167.

Cohen, L., \& Dehaene, S. (2004). Specialization within the ventral stream: The case for the visual word form area. Neuroimage, 22(1), 466-476.

Cohen, L., Martinaud, O., Lemer, C., Lehericy, S., Samson, Y., Obadia, M., et al. (2003). Visual word recognition in the left and right hemispheres: Anatomical and functional correlates of peripheral alexias. Cerebral Cortex, 13(12), 1313-1333.

Coslett, H. B., \& Monsul, N. (1994). Reading with the right-hemisphere-Evidence from transcranial magnetic stimulation. Brain and Language, 46(2), $198-211$.

Coslett, H. B., \& Saffran, E. M. (1989). Evidence for preserved reading in pure alexia. Brain, 112, 327-359.

Coslett, H. B., \& Saffran, E. M. (1994). Mechanisms of implicit reading in pure alexia. In M. J. Farah, \& G. Ratcliff(Eds.), The neuropsychology of highlevel vision. Hillsdale, NJ: Lawrence Erlbaum Associates, Inc.

Coslett, H. B., Saffran, E. M., Greenbaum, S., \& Schwartz, H. (1993). Reading in pure alexia-The effect of strategy. Brain, 116, 21-37.

Davis, C. J. (2005). N-Watch: A program for deriving neighborhood size and other psycholinguistic statistics. Behavior Research Methods, 37(1), 65-70.

Doctor, E. A., Sartori, G., \& Saling, M. M. (1990). A letter-by-letter reader who could not read nonwords. Cortex, 26(2), 247-262.

Farah, M. J., \& Wallace, M. A. (1991). Pure alexia as a visual impairment: A reconsideration. Cognitive Neuropsychology, 8(3-4), 313-334.

Feinberg, T. E., Dyckesberke, D., Miner, C. R., \& Roane, D. M. (1995). Knowledge, implicit knowledge and metaknowledge in visual agnosia and pure alexia. Brain, $118,789-800$.

Friedman, R. B., \& Alexander, M. P. (1984). Pictures, images, and pure alexia-A casestudy. Cognitive Neuropsychology, 1(1), 9-23.

Henry, C., Gaillard, R., Volle, E., Chiras, J., Ferrieux, S., Dehaene, S., et al. (2005). Brain activations during letter-by-letter reading: A follow-up study. Neuropsychologia, 43(14), 1983-1989.

Howard, D. (1991). Letter-by-letter readers: Evidence for parallel processing. In D. Besner, \& D. W. Humphreys (Eds.), Basic processes in reading: Visual word recognition. Hillsdale, NJ: Lawrence Erlbaum Associates, Inc.

Howard, D., \& Patterson, K. (1992). Pyramids and palm trees: A test of semantic access from pictures and words. Bury St. Edmunds, England: Thames Valley Test Company.

Kasten, E., Strasburger, H., \& Sabel, B. A. (1997). Programs for diagnosis and therapy of visual field deficits in vision rehabilitation. Spatial Vision, 10(4), 499-503.

Kay, J., Lesser, R., \& Coltheart, M. (1992). Psycholinguistic assessments of language processing in aphasia (PALPA). Erlbaum: Hove.

Kucera, H., \& Francis, W. N. (1967). Computational analysis of present-day American English. Providence, RI: Brown University Press.

Lambon Ralph, M. A., Hesketh, A., \& Sage, K. (2004). Implicit recognition in pure alexia: The Saffran effect-a tale of two systems or two procedures? Cognitive Neuropsychology, 21(2-4), 401-421.

McClelland, J. L., \& Rumelhart, D. E. (1981). An Interactive activation model of context effects in letter perception. 1. An account of basic findings. Psychological Review, 88(5), 375-407.

Mycroft, R. H., Behrmann, M., \& Kay, J. (2009). Visuoperceptual deficits in letter-byletter reading? Neuropsychologia, 47(7), 1733-1744.

Patterson, K., \& Kay, J. (1982). Letter-by-letter reading: Psychological descriptions of a neurological syndrome. Quarterly Journal of Experimental Psychology, 34A(August), 411-441.

Patterson, K., \& Marcel, A. (1992). Phonological ALEXIA or PHONOLOGICAL alexia? In J. Alegria, D. Holender, J. Junca de Morais, \& M. Radeau (Eds.), Analytic approaches to human cognition. Amsterdam: Elsevier.

Plaut, D. C., \& Shallice, T. (1993). Perseverative and semantic influences on visual object naming errorsin optic aphasia-A connectionist account. Journal of Cognitive Neuroscience, 5(1), 89-117.

Price, C. J., \& Humphreys, G. W. (1992). Letter-by-letter reading-Functional deficits and compensatory strategies. Cognitive Neuropsychology, 9(5), 427-457.

Price, C. J., \& Humphreys, G. W. (1995). Contrasting effects of letter-spacing in alexia-Further evidence that different strategies generate word-length effects in reading. Quarterly Journal of Experimental Psychology Section a-Human Experimental Psychology, 48(3), 573-597.

Pyun, S. B., Sohn, H. J., Jung, J. B., \& Nam, K. (2007). Differential reorganization of fusiform gyrus in two types of alexia after stroke. Neurocase, 13(5-6), 417-425.

Röder, B., Kusmierek, A., Spence, C., \& Schicke, T. (2007). Developmental vision determines the reference frame for the multisensory control of action. Proceedings of the National Academy of Sciences of the United States of America, 104(11), 4753-4758.

Saffran, E. M., \& Coslett, H. B. (1998). Implicit vs. letter-by-letter reading in pure alexia: A tale of two systems. Cognitive Neuropsychology, 15(1-2), 141-165.

Schneider, W., Eschman, A., \& Zuccolotto, A. (2002). E-Prime user's guide. Pittsburgh: Psychology Software Tools.

Shallice, T., \& Saffran, E. (1986). Lexical processing in the absence of explicit word identification-Evidence from a letter-by-letter reader. Cognitive Neuropsychology, 3(4), 429-458. 
Starrfelt, R., Habekost, T. \& Gerlach, C. (2010). Visual processing in pure alexia: A case study. Cortex, 46(2), 242-255.

Warrington, E. K., \& James, M. (1991). The visual object and space perception battery. Bury St. Edmunds, Suffolk: Thames Valley Test Company.
Warrington, E. K., \& Shallice, T. (1980). Word-form dyslexia. Brain, 103(March), 99-112.

Weekes, B. S. (1997). Differential effects of number of letters on word and nonword naming latency. Quarterly Journal of Experimental Psychology, 50A(2), 439-456. 